\title{
Silicified Anisian (Middle Triassic) spiriferinid brachiopods from Guizhou, South China
}

\author{
Zuoyu Sun, Weicheng Hao, Sun Yuanlin, and Dayong Jiang \\ Acta Palaeontologica Polonica 54 (1), 2009: 61-68 doi:http://dx.doi.org/10.4202/app.2009.0107
}

A newly discovered silicified brachiopod interval from the UpperMember of the Guanling Formation (Late Anisian, Middle Triassic) in Guizhou Province (South China) is described for the first time. The most remarkable feature of this brachiopod assemblage, besides the very good preservation, is the very low taxonomic evenness and diversity. This impoverished, low diversity/high density assemblage is represented by more than 700 recovered specimens belonging to three species within two spiriferinid genera (Pseudospiriferina multicostata, $P$. pinguis, and Punctospirella fragilis). It is characterized by the overwhelming abundance of an endemic spiriferinid species, $P$. multicostata, which contributes to more than $90 \%$ of the community. Silicified valves of $P$. multicostata and Punctospirella fragilis allow detailed descriptions of the internal morphology based on direct observation. Brachiopod paleoecology, assessed by considering host-rock lithology, shell disarticulation, and shell size suggests that this endemic brachiopod fauna represents a favourable niche for development of dense brachiopod-dominated communities, i.e., high energy, hard substrate, nutrient rich environment.

Key words: Brachiopoda, Spiriferinida, Anisian, Triassic, China

Zuoyu Sun [sunzuoyu@pku.edu.cn], Weicheng Hao [whao@pku.edu.cn], Yuanlin Sun [ylsun@pku.edu.cn], and Dayong Jiang [djiang@pku.edu.cn], Department of Geology and Geological Museum, Peking University, Beijing 100871, P. R. China

This is an open-access article distributed under the terms of the Creative Commons Attribution License (for details please see creativecommons.org), which permits unrestricted use, distribution, and reproduction in any medium, provided the original author and source are credited. 
Fof Full text $(427.7 \mathrm{kB})$ 